\title{
AN EXPERIMENTAL ASSESSMENT OF THE PLATE HEAT EXCHANGER CHARACTERISTICS BY WILSON PLOT METHOD
}

\author{
Jan Opatřil, Jan Havlík, Ondřej Bartoš*, Tomáš DlouhÝ \\ CTU in Prague, Department of Energy Engineering, Technická 4, 16607 Praha, Czechia \\ * corresponding author: ondrej.bartos@fs.cvut.cz
}

ABstract. An aim of this paper is a suggestion of the evaluation method based on the experimental data and the Wilson plot method for the Plate Heat Exchangers (PHE). For the purpose of the project, a new experimental loop was built for the testing of PHE to obtain the overhaul heat transfer coefficient and pressure drop between the inlet and outlet of the fluid. The measurement were done for three different PHE, with the performance range of $30-100 \mathrm{~kW}$. The working fluid was water on both sides of the PHE. The differences are in number of pates as well as in extrusion profiles. The Wilson plot evaluation method was involved in the processing of the experimental data. To obtain more accurate correlations between the experimental data and theoretical results yielded by the Wilson plot, the method was enhanced by the measured pressure drop involving. This approach could be useful for PHE designing software and for the manufacturing company.

KEYWORDS: plate heat exchanger; Wilson plot; experimental measurement; heat transfer; pressure drop; friction factor.

\section{INTRODUCTION}

Plate heat exchangers (PHE) are the group of heat exchangers generally characterized by their compactness and flexibility. The PHE could be commonly used for a wide range of fluids include the non-Newtonian liquids. On the other side, their application is limited by relatively low allowable media pressure difference, which arises from the construction. PHEs are typically corrugated from the thin metal plates which are providing the large heat transfer surface. The configuration of the plates has the influence on both important parameters, pressure drop and heat transfer. Several different plate patterns were developed worldwide to reach the desired operation parameters. For the purpose of this work, three pattern configurations called Chevron, Tubular and Dimpel were tested [1, 2].

The main goal of the paper is to suggest the method to validate the criterial equation applied for the PHE design from the easily measured parameters. The temperatures of the fluid at the inlet and outlet, the flow rate on both sides and the pressure drop were considered. The first step was the experimental determination of the overall heat transfer coefficient (OHTC) in the PHE. All the achieved data were further used for the evaluation of the heat transfer coefficient on both sides of the plates.

Equations for PHE characterisation are available for the most used patterns in literature [1, 2]. The number of researchers experimentally investigated different plate patterns to describe their basic characteristics by newly developed criterial equations [3] and some researchers focused work on heat exchanger optimization, e.g. [7, 8]. The presented work suggests a similar way but with the basic knowledge of the geometrical characteristics of plate patterns. The advantage of the approach is possibility to verify or recalculate existed PHEs. The modification of Wilson plot technique was involved to obtain the new equations.

A necessary for the project was to develop and manufacture the testing stand for the measurement of the OHTC. In the second part, the experimental investigation was carried out on the three PHE. The PHEs differ in the pattern of the plates used as heat exchanging surfaces. The Chevron, Tubular and Dimpel type of the metal sheet pattern was used. The measurement was performed with water on both sides of each PHE.

\section{EXPERIMENTAL SET-UP}

The testing loop was built in the laboratory of CTU in Prague in the year 2014 as the part of the project with an industrial partner. The aim was the stand for the variable measuring of the PHE. Automatic controlled biomass boiler "comp. Fiedler s.r.o.", with the performance range $30-100 \mathrm{~kW}$, was chosen as a heat source. For the PHE cooling, a water loop with the maximum cooling capacity in the laboratory $(300 \mathrm{~kW})$, was used. The schema of the measurement loop is in Figure 1 .

The design of the testing loop was solved as the combination of available facilities in laboratories, the boiler and the cooling tower, and demands for measurement of required physical quantities. In comparison with generally recommended schemes, a hydraulic separator is included.

The hydraulic separator was involved to separate the PHE loop and the boiler loop on the heating water side. This solution brings the advantage of the independence of the heat transfer in the boiler itself, because the hydraulic condition in the boiler is nearly constant and it is independent on the flow condition 


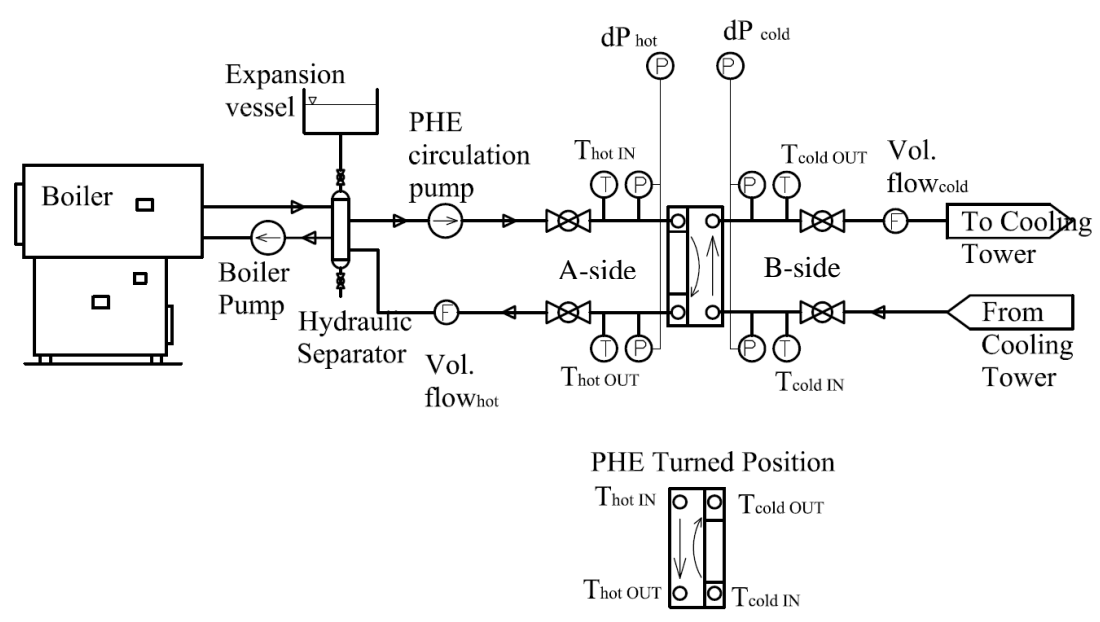

Figure 1. The schema of the measurement set-up.

in the PHE for varying mass flow. The PHE was isolated with polystyrene foam.

\section{THE METHOD}

The method of the experimental research was chosen with the respect of the limited knowledge of the PHE parameters. The measurements were performed for four different conditions. First three conditions were different only by the performance of the boiler. This means that hot water from the boiler flow through the A-side of PHE (see Figure 1). In each of the conditions, 4 flow rates in the PHE were tested. The performance of the boiler was adjusted by different timing of the fuel supply.

The forth condition was measured while the PHE was turned around to commute the hot and cold water. In this case, hot water was flowing through the B-side of the PHE. This method can help to determine the OHTC and, moreover, helps with the evaluation of the heat transfer coefficient for each side using the Wilson plot method.

The data processing to yield the OHTC is straightforward from the measured parameters of temperature and pressure The density of the water and heat capacity is computed from the IAWPS IF97, a mean temperature between inlet and outlet is expected.

The performance of the hot and cold side of the PHE can be written as

$$
\begin{aligned}
Q_{\text {hot }} & =c_{\mathrm{p}, \text { hot }} \varrho_{\text {hot }} \text { Vol.flow } \\
Q_{\text {cold }} & \left.=c_{\mathrm{p}, \text { cold }} \varrho_{\text {cold }} \text { Vol.flow } T_{\text {hot,in }}-T_{\text {hot }, \text { out }}\right) \\
& \left(T_{\text {cold }, \text { in }}-T_{\text {cold }, \text { out }}\right)
\end{aligned}
$$

(both in $[\mathrm{kW}]$ ).

The area of the heating surface $A\left[\mathrm{~m}^{2}\right]$ is unknown for all tested exchangers. The determination of the OHTC can be done only in combination with $A$ by following equation:

$$
O H T C^{*}=O H T C \cdot A=\frac{Q_{\mathrm{hot}}+Q_{\mathrm{cold}}}{2 L M T D}[\mathrm{~kW} / \mathrm{K}] .
$$

Logarithmic mean temperature difference is defined for the testing loop as

$$
L M T D=\frac{\left(T_{\text {hot }, \text { in }}-T_{\text {cold }, \text { out }}\right)-\left(T_{\text {hot }, \text { out }}-T_{\text {cold }, \text { in }}\right)}{\ln \frac{T_{\text {hot,in }}-T_{\text {cold }, \text { out }}}{T_{\text {hot }, \text { out }}-T_{\text {cold }, \text { in }}}}
$$

(in $[K])$.

\subsection{Wilson PLOT METHOD}

Most of the convective heat transfer processes inherent to heat exchangers usually involve complex geometries and complicated flows so analytical solutions are not possible. In many cases, there are several empirical methods to calculate the HTC for a similar type of heat exchanger and geometry, which provide different results 9 .

The Wilson plot method is a suitable technique to estimate the convection coefficients in a variety of convective heat transfer processes. The method avoids the direct measurement of the surface temperature and the disturbance of the fluid flow and heat transfer introduced while attempting to measure those temperatures. It relies on the fact that the overall thermal resistance can be extracted from experimental measurements in a reliable manner. The aim of the method is the calculation of the convection coefficient (or thermal resistance) of the fluid in the criterion formula for the defined type of the convection heat transfer. The application of the Wilson plot method is based on the measurement of the experimental mass flow rate and temperatures [1].

The original method has been derived for the processes of transferring heat by convection, when the thermal resistance on one side of the heat transfer surface remains constant (in the case of condensation [10]) while varying the mass flow on the other side changes the total thermal resistance in the heat exchanger. This method was originally derived for determining the coolant HTC in steam condensers, where the sensitivity of the shell-side HTC value to 
the overall HTC is more significant than the condensation HTC [10]. Modifications of the Wilson plot method based on the principle have been derived for wide range of heat exchanger geometries.

\subsection{Evaluating PARAmeters of Plate HEAT EXCHANGERS}

In the case of the plate heat exchangers, the hydraulic diameter is very small, almost in order of $\mathrm{mm}$. Therefore, the turbulent conditions are achieved very early. The Reynolds number is a function of the fluid flow rate. The mathematical formula for the Reynolds number is given in (1). The ratio represents momentum to viscous forces:

$$
R e=\frac{u D}{v} .
$$

The Prandtl number is a function of two important physical properties (thermal and momentum). The Prandtl number may be seen as a ratio of the rate that viscous forces penetrate the material to the rate that thermal energy penetrates the material:

$$
\operatorname{Pr}=\frac{\mu c_{\mathrm{p}}}{k} .
$$

The Nusselt number is equal to the dimensionless temperature gradient at the surface and it essentially provides a measure of convective heat transfer. The Nusselt number may be viewed as a ratio of the conduction resistance of a material to the convection resistance of the same material:

$$
N u=\frac{h D}{k} .
$$

In single phase fluid flow heat transfer, generally, $\mathrm{Nu}$ is represented by a pragmatic expression such as the one given in $(3)$. The term $\left(\mu / \mu_{\mathrm{w}}\right)$ is accountable for variable viscosity effects:

$$
N u=C \operatorname{Re}^{n} \operatorname{Pr}^{m}\left(\frac{\mu}{\mu_{\mathrm{w}}}\right)^{0.14} .
$$

\subsection{The Wilson PlOT MODIFiCATION}

The derivation of the Wilson plot method is based on the heat balance of the heat transfer in a heat exchanger [1]. The thermal heat resistance $R$, in this process, is determined from the enthalpy change of the fluid:

$$
R=\frac{1}{U A}=\frac{L M T D}{m_{1} c_{\mathrm{p}, 1}\left(T_{1, \mathrm{out}}-T_{1, \mathrm{in}}\right)} .
$$

The overall heat transfer coefficient $U$ can be expressed as

$$
\frac{1}{U}=\frac{1}{h_{\mathrm{A}}}+\frac{s}{k_{\mathrm{w}}}+\frac{1}{h_{\mathrm{B}}},
$$

where

$$
\begin{aligned}
h_{\mathrm{A}} & =\frac{k_{\mathrm{A}}}{D_{\mathrm{A}}} C_{\mathrm{A}} \operatorname{Re}_{\mathrm{A}}^{n} \operatorname{Pr}_{\mathrm{A}}^{m}\left(\frac{\mu}{\mu_{\mathrm{w}}}\right)_{\mathrm{A}}^{0.14}, \\
h_{\mathrm{B}} & =\frac{k_{\mathrm{B}}}{D_{\mathrm{B}}} C_{\mathrm{A}} \operatorname{Re}_{\mathrm{B}}^{n} \operatorname{Pr}_{\mathrm{B}}^{m}\left(\frac{\mu}{\mu_{\mathrm{w}}}\right)_{\mathrm{B}}^{0.14} .
\end{aligned}
$$

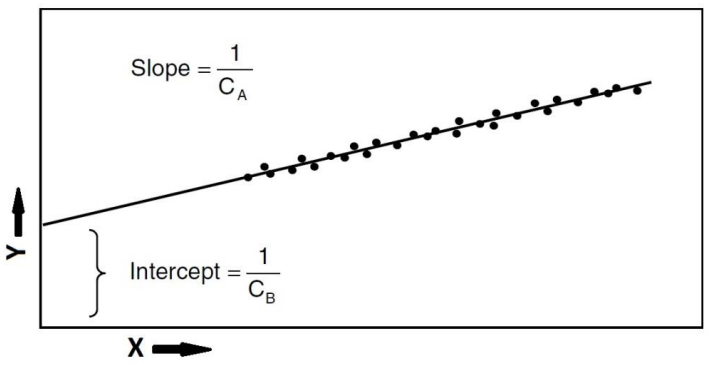

FiguRE 2. Evaluation of the criterial equation [1].

By the substitution of terms in (5), (6) to $(4)$, there is given:

$$
\begin{aligned}
\left(\frac{1}{U}-\frac{s}{k_{\mathrm{w}}}\right) & \frac{k_{\mathrm{A}}}{D_{\mathrm{A}}} \operatorname{Re}_{\mathrm{A}}^{n} \operatorname{Pr}_{\mathrm{A}}^{m}\left(\frac{\mu}{\mu_{\mathrm{w}}}\right)_{\mathrm{A}}^{0.14} \\
& =\frac{1}{C_{\mathrm{A}}}+\frac{\frac{k_{\mathrm{A}}}{D_{\mathrm{A}}} \operatorname{Re}_{\mathrm{A}}^{n} \operatorname{Pr}_{\mathrm{A}}^{m}\left(\frac{\mu}{\mu_{\mathrm{w}}}\right)_{\mathrm{A}}^{0.14}}{C_{\mathrm{B}} \frac{k_{\mathrm{B}}}{D_{\mathrm{B}}} \operatorname{Re}_{\mathrm{B}}^{n} \operatorname{Pr}_{\mathrm{B}}^{m}\left(\frac{\mu}{\mu_{\mathrm{w}}}\right)_{\mathrm{B}}^{0.14}}
\end{aligned}
$$

It is possible to write 77 in a linear form

$$
Y_{1}=a X_{1}+b,
$$

where $Y_{1}$ and $X_{1}$ are in following forms:

$$
\begin{aligned}
Y_{1} & =\left(\frac{1}{U}-\frac{s}{k_{\mathrm{w}}}\right) \frac{k_{\mathrm{A}}}{D_{\mathrm{A}}} \operatorname{Re}_{\mathrm{A}}^{n} \operatorname{Pr}_{\mathrm{A}}^{m}\left(\frac{\mu}{\mu_{\mathrm{w}}}\right)_{\mathrm{A}}^{0.14}, \\
X_{1} & =\frac{\frac{k_{\mathrm{A}}}{D_{\mathrm{A}}} \operatorname{Re}_{\mathrm{A}}^{n} \operatorname{Pr}_{\mathrm{A}}^{m}\left(\frac{\mu}{\mu_{\mathrm{w}}}\right)_{\mathrm{A}}^{0.14}}{\frac{k_{\mathrm{B}}}{D_{\mathrm{B}}} \operatorname{Re}_{\mathrm{B}}^{n} \operatorname{Pr}_{\mathrm{B}}^{m}\left(\frac{\mu}{\mu_{\mathrm{w}}}\right)_{\mathrm{B}}^{0.14}} .
\end{aligned}
$$

The set of values of $Y$ and $X$, given for the set of experimental data, can be fitted by the linear regression for an estimated value of the coefficient $n$. The value, pragmatically used for the coefficient $m$, is 0.4 in the transfer process [3].

Coefficients $a, b$ are determined as the result of the linear regression

$$
a=\frac{1}{C_{\mathrm{A}}}, \quad b=\frac{1}{C_{\mathrm{B}}} .
$$

The $X$ and $Y$ regression starts with an initial $n$ value as well as a guess for the $C_{\mathrm{B}}$ value. These values have an impact on the wall temperature calculations; therefore, the viscosity ratio must be adjusted in both linear regression processes. From the $X_{1}$ and $Y_{1}$ regression, $C_{\mathrm{A}}$ and $C_{\mathrm{B}}$ coefficients are found. This $C_{\mathrm{B}}$ coefficient is then used in a mathematical relaxation method to converge the viscosity ratio in the $X_{2}$ and $Y_{2}$ linear regression, producing values of $n$ and $C_{\mathrm{A}}$. The new $\mathrm{n}$ is then used in the next iteration of regressions (which has the new viscosity ratios to be relaxed). The calculations continue following this procedure until the difference between the successive $n$ and $C_{\mathrm{B}}$ values and the $C_{\mathrm{A}}$ values from the $X_{1}-Y_{1}$ and $X_{2}-Y_{2}$ linear regressions reach a predetermined allowable error [11]. 


\begin{tabular}{lccc}
\hline Heat exchanger & Chevron & Dimpel & Tubular \\
\hline Cold side & 2.79 & 1.80 & 1.77 \\
Hot side & 8.61 & 2.88 & 2.97 \\
\hline
\end{tabular}

TABLE 1. Resulting values of coefficient $C_{\bmod }$.

\begin{tabular}{lc}
\hline Fluid flow & \multicolumn{1}{c}{ Friction factor } \\
\hline Laminar & $f=1.328 R e^{-1 / 2}$ \\
Turbulent & $f=0.074 R e^{-1 / 5}$ \\
Transition & $f=0.074 R e^{-1 / 2}-174 R e^{-1}$ \\
\hline
\end{tabular}

TABle 2. Friction factor dependence on the fluid flow 3 .

\begin{tabular}{lccc}
\hline & Exponent $2+b$ & $b$ & $b$ \\
\hline Chevron & 1.7302 & -0.2608 & $-1 / 3.8$ \\
Tubular & 1.8134 & -0.1866 & $-1 / 5.4$ \\
Dimpel & 1.7918 & -0.2086 & $-1 / 4.8$ \\
\hline
\end{tabular}

TABle 3. Coefficients on the A-side of the PHE.

\begin{tabular}{lccc}
\hline & Exponent $2+b$ & $b$ & $b$ \\
\hline Chevron & 1.5074 & -0.4926 & $-1 / 2.0$ \\
Tubular & 1.6261 & -0.3739 & $-1 / 2.7$ \\
Dimpel & 1.515 & -0.485 & $-1 / 2.1$ \\
\hline
\end{tabular}

TABle 4. Coefficients on the B-side of the PHE.

In our case, when the evaluation method should be independent on the geometry of the PHE, one can expect following suggestions. The velocity for the determination of the Reynolds number can be given as $v=\frac{V}{S}$. Thus (2) and (3) are transformed to the term

$$
h=\frac{k}{D} C\left(\frac{V D}{S v}\right)^{n} \operatorname{Pr}^{m}\left(\frac{\mu}{\mu_{\mathrm{w}}}\right)^{0.14} .
$$

The values of the parameters $D, S$ are unknown, but these parameters are constant for the specific geometry of a heat exchanger. Therefore, we introduce the modified Reynolds number, defined as $R e_{\bmod }=\frac{V}{v}$ and the unknown parameters $D, S$ are included to the constant $C_{\mathrm{mod}}=C \frac{D^{n}}{D S^{n}}$. Equation $(6)$ is transformed to the term

$$
h=C_{\bmod } k \operatorname{Re}_{\bmod }^{n} \operatorname{Pr}^{m}\left(\frac{\mu}{\mu_{\mathrm{w}}}\right)^{0.14}
$$

which is used in the calculation below instead of the terms in 2 and (3).

According to the calculation procedure below, the value of the coefficient $m$ was defined as 0.4 and the value of the coefficient $n$ was calculated as approximately 0.9 , which is the best corresponding in each type of the testing plate heat exchangers. The resulting values of coefficient $C_{\bmod }$ are shown in Table 1 .

The results in Table 1 show that the heat transfer coefficient is higher on the hot side of the PHE. For

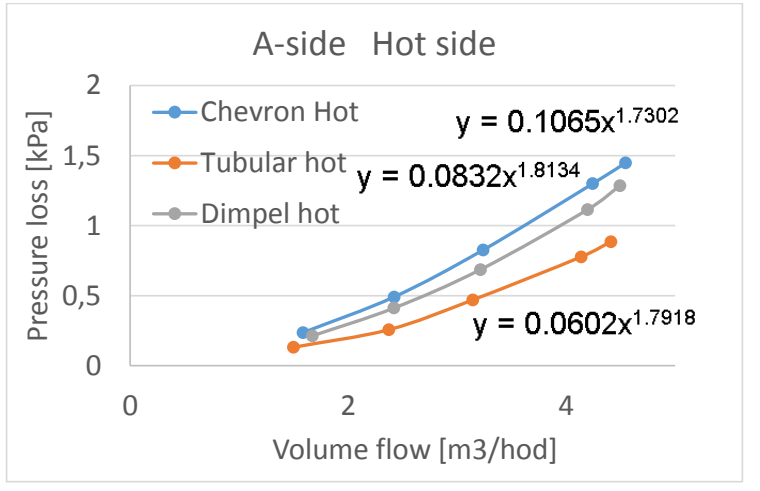

Figure 3. Evaluation of the pressure losses dependence on the A-side.

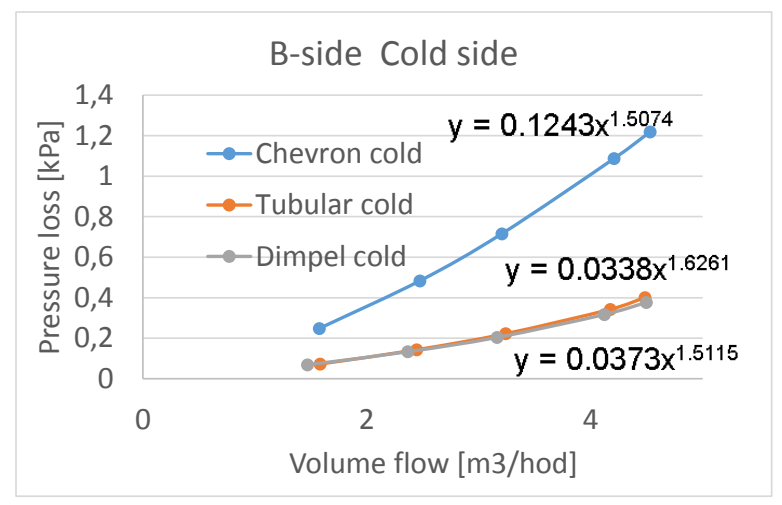

Figure 4. Evaluation of the pressure losses dependence on the A-side.

the explanation of the convection coefficient difference, the analysis of the pressure losses were done.

\subsection{Pressure LOSSES}

The pressure loss is defined as

$$
\Delta p=f \frac{4 L}{D_{\mathrm{e}}} \frac{\varrho u^{2}}{2},
$$

where $f$ is the friction factor [3]. Its value for a plate exchanger is according to the flow type, see Table 2

$$
\begin{aligned}
f & =a R e^{b}=a\left(\frac{u D_{e}}{v}\right)^{b}, \\
u & =\frac{\dot{V}}{S} \\
\Delta p & =2 a \frac{L}{D_{\mathrm{e}}^{1-b}} \frac{\varrho}{v^{b} S^{2+b}} \dot{V}^{2+b}=A \dot{V}^{2+b} .
\end{aligned}
$$

The measured dependence between the pressure loss and the volume flow of water for both sides of PHE is presented in Figures 3 and 4 . Measured data were fit with an exponential function and coefficients of the functions are in Tables 3 and 4

Results in Table 3 correspond with the turbulent flow and the coefficient $-1 / 5$. Results in Table 4 correspond with the laminar flow and the coefficient of $-1 / 2$. 

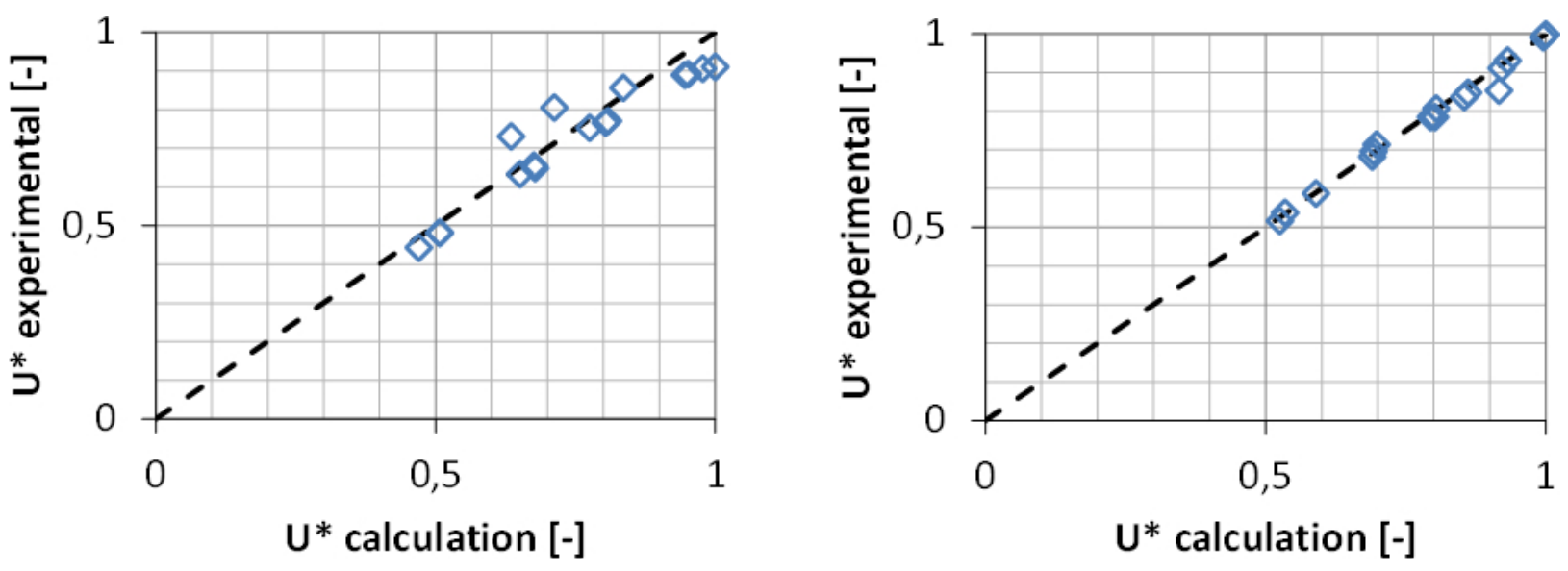

Figure 5. The quality of the model for the Chevron and Dimpel PHE.

The analysis of the measured data indicates that on the A-side, the turbulent flow is established and on the B-side, the flow is mostly laminar. This interesting result could be useful for the manufacturer. For example, an increase of the turbulence intensity on the B-side could possibly enhance the performance.

\section{Conclusion}

The method for the validation of the PHE design was suggested. The application of the Wilson plot method, together with the pressure loss analysis, brought the powerful tool for the verification and the design of the PHE for their producers. Main advantage is the application of simply measured parameters (temperature, flow rate and pressure loss) to reach dependence of the heat transfer coefficients on the flow rate of the fluid. This method is even suitable for the cases, when a similar fluid, with similar order of the convection coefficient, is on both sides of the PHE.

The analysis of pressure losses can increase reliability of the standard Wilson plot method. In our case, the proof of the mostly turbulent flow on the hot side and mostly laminar flow on the cold side for all three PHE types, was brought. In Figure 5 the agreement between suggested model and experimental data is plotted in the normalized units.

The data used for the data processing were measured while the entire measurement system was in the equilibrium. This state should be identified by the low difference between the performance on the cold and hot side. The difference between performance of the cold and hot side of the PHE can be expected as the uncertainty of the measurement. The sensitivity analysis brought the result that entire uncertainty of the PHE side performance should be smaller than $3 \%$. Main contribution is coming from the uncertainty of the temperature measurement. Most of the measurements are in the range of the expected error.

The conclusions, results and data reported in this paper introduce a good basic approach to evaluate parameters PHE with unknown geometrical parameters. Further tests would be beneficial to extend present knowledge of the PHE parameter to the region exceeding the tested ranges.

\section{LIST OF SYMBOLS}

$A$ heat transfer area $\left[\mathrm{m}^{2}\right]$

$C$ constant

$c_{\mathrm{p}} \quad$ specific heat capacity $[\mathrm{kJ} / \mathrm{kg} \mathrm{K}]$

$D$ characteristic diameter $(\mathrm{m})$

$h$ convection coefficient $\left[\mathrm{W} /\left(\mathrm{m}^{2} \mathrm{~K}\right)\right]$

$k$ thermal conductivity $[\mathrm{W} / \mathrm{m} \mathrm{K}]$

LMTD logarithmic mean temperature difference $[\mathrm{K}]$

$m$ mass flow rate $[\mathrm{kg} / \mathrm{s}]$

$\mathrm{Nu}$ Nusselt number

$\operatorname{Pr}$ Prandtl number

$R$ thermal resistance $[\mathrm{K} / \mathrm{W}]$

Re Reynolds number

$s$ wall thickness $[\mathrm{m}]$

$S$ flow cross-section $\left[\mathrm{m}^{2}\right]$

$T$ temperature $[\mathrm{K}]$

$U$ overall heat transfer coefficient $\left[\mathrm{W} / \mathrm{m}^{2} \mathrm{~K}\right]$

$v$ velocity $[\mathrm{m} / \mathrm{s}]$

\section{SUBSCRIPTS}

A fluid A

B fluid B

in inlet

1 liquid

out outlet

$\mathrm{w}$ wall

\section{SUPERSCRIPTS}

$m$ exponent of Prandtl number

$n$ exponent of Reynolds number

* normalized value

\section{ACKNOWLEDGEMENTS}

The authors gratefully acknowledge the support of all colleagues from G.A.M. HEAT spol. s.r.o. who helped to finish this project. This work has been supported by the Grant Agency of the Czech Technical University in Prague, grant No. SGS 14/183. 


\section{REFERENCES}

[1] J. Fernández-Seara, F. J. Uhía, J. Sieres a A. Campo. „A general review of the Wilson plot method and its modifications to determine convection coefficients in heat exchange devices". Applied Thermal Engineering, p. $2745-2757,2007$.

[2] R. K. Shah, D. P. Sekulic., Fundamentals of Heat Exchanger Design, New York, Wiley, 2003.

[3] R. L. Pradhan, D. Ravikumar, D. L. Pradhan. „Review of Nusselt Number Correlation for Single Phase Fluid Flow through a Plate Heat Exchanger to Develop C\# Code Application Software“. Journal of Mechanical and Civil Engineering, pp. 01-08, 2013. ISSN (e): 2278-1684, ISSN (p): 2320-334X.

[4] A. Hashmi, F. Tahir, U. Hameed. „Empirical Nusselt Number Correlation for Single Phase Flow Through a Plate Heat Exchanger". Recent Advances in Fluid Mechanics, Heat \& Mass Transfer and Biology (2011).

[5] S. D. Pandey, V. K. Nema. „Investigation of the Performance Parameters of an Experimental Plate Heat Exchanger in Single Phase Flow". International Journal of Energy Engineering. 2011; 1(1): 19-24. DOI:10.5923/j.ijee.20110101.04

[6] F. Akturk, G. Gulben, S. Aradag, N. Sezer Uzol, S. Kakac. „Experimental Investigation of the
Characteristics of a Chevron Type Gasketed-Plate Heat Exchanger". 6th International Advanced Technologies Symposium (IATS'11), 16-18 May 2011, Elazı̆̆, Turkey.

[7] J. M. Pinto, J. A. W. Gut. „A Screening Method for the Optimal Selection of Plate Heat Exchanger Configurations". Brazilian Journal of Chemical Engineering, Vol. 19, No. 04, pp. 433 - 439, October December 2002. ISSN 0104-6632.

[8] V. R. Naik, V. K. Matawala. „Experimental Investigation of Single Phase Chevron Type Gasket Plate Heat Exchanger". International Journal of Engineering and Advanced Technology (IJEAT), Volume-2, Issue-4, April 2013. ISSN: 2249 - 8958.

[9] J. Havlík, T. Dlouhý. Experimental Verification of Theoretical Models to Calculate the Heat Transfer Coefficient in the Shell-and-Tube Heat Exchanger. In 20 th International Conference Engineering Mechanics 2014. Brno: Brno University of Technology, 2014, p. 216-219. ISBN 978-80-214-4871-1. Web of Science: 000364573900047.

[10] Havlík, J. a T. Dlouhý. Condensation of Water Vapour in a Vertical Tube Condenser. Acta Polytechnica. 2015, vol. 55, no. 5, p. 306-312. ISSN 1210-2709. Scopus: 2-s2.0-84946073960.

[11] G. F. Hewitt, G. L. Shires a t. R. Bott, Process Heat Transfer, New York: Begell House, 2000. 